\begin{tabular}{|c|l|}
\hline Title & Activity-dependent regulation of BRINP family genes \\
\hline Author(s) & Motomiya, Makoto; Kobay ashi, Makoto; Iwasaki, Norimasa; Minami, A kio; Matsuoka, Ichiro \\
\hline Citation & $\begin{array}{l}\text { Biochemical and Biophysical Research Communications, 352(3), 623-629 } \\
\text { https://doi.org/10.1016/.bbrc.2006.11.072 }\end{array}$ \\
\hline Issue Date & $2007-01-19$ \\
\hline Doc URL & http://hdl.handle.net/2115/17196 \\
\hline Type & article (author version) \\
\hline File Information & B\&BRC352-3.pdf \\
\hline
\end{tabular}

Instructions for use 


\title{
Activity-Dependent Regulation of BRINP Family Genes
}

\author{
Makoto Motomiya, M.D. ${ }^{* 1}{ }^{* 2}$, Miwako Kobayashi, Ph.D. ${ }^{* 1}{ }^{* 3}$, Norimasa Iwasaki, M.D, \\ Ph.D. ${ }^{* 2}$, Akio Minami, M.D, Ph.D. ${ }^{* 2}$, Ichiro Matsuoka Ph.D. ${ }^{* 1 * 3}$
}

*1. Division of Innovative Research, Creative Research Initiative 'SOUSEI' (CRIS), Hokkaido University, Sapporo 001-0021, JAPAN

*2. Department of Orthopedic Surgery, Graduate School of Medicine, Hokkaido University, Sapporo 060-8638, JAPAN

*3. Laboratory of Neuroscience, Graduate School of Pharmaceutical Sciences, Hokkaido University, Sapporo 060-0812, Japan

Manuscript for Biochemical and Biophysical Research Communications

Numbers of pages: Text pages, 18 .

Numbers of figures, 4.

\section{Correspondence to:}

Ichiro Matsuoka Ph.D.

Division of Innovative Research,

Creative Research Initiative 'SOUSEI' (CRIS),

Hokkaido University

Kita-21 Nishi-10, Kita-ku, Sapporo, 001-0021, JAPAN.

Phone: +81-11-706-9023, Fax +81-11-706-9023

E-mail: matsuoka@pharm.hokudai.ac.jp 


\begin{abstract}
We previously identified a family of novel developmentally regulated genes: BRINP1, 2, and 3, which are predominantly and widely expressed in the CNS from earlier developmental stages to adulthood. In the present study, we investigated the activity-dependent regulation of BRINP expression in the CNS. Among the three BRINP genes, BRINP1-mRNA was specifically up-regulated in the dentate gyrus of mouse hippocampus by kainic acid treatment. In cultured hippocampal neurons, the induction of BRINP1-mRNA was also observed by the activation of glutamate receptors. Although BDNF-mRNA is up-regulated in a similar activity-dependent manner, BDNF itself did not induce BRINP1-mRNA. From these results, the physiological roles of the activity-dependent induction of BRINP1-mRNA are discussed.
\end{abstract}

Key words: Hippocampus, BMP/RA-Inducible Neural-specific Protein, BRINP, Activity-dependent gene expression, Cell Cycle 


\section{INTRODUCTION}

Activity-dependent regulation of gene expression in the mature nervous system is closely associated with fundamental functions of the nervous system in both a physiological and pathological contexts. Physiologically, activity-dependent neural gene expression forms the basis of synaptic plasticity including learning and memory formation [1]. Alterations of neural activity in pathological conditions such as trauma, ischemia, and neurodegenerative disease also induce various sets of genes which play important roles in neuroprotective response or neuronal cell death [2]. Augmentation of neural activity causes the activation of a voltage-dependent $\mathrm{Ca}^{2+}$ channel by membrane depolarization in the CNS and results in the elevation of intracellular $\mathrm{Ca}^{2+}$, which triggers, various signal transduction pathways leading to the induction of specific sets of genes [3].

Recently, we identified a novel family of neural-specific genes, BRINP1, 2, and 3, which have been predominantly and widely expressed in the CNS from earlier developmental stages $[4 ; 5]$. The primary structures of the protein products have been highly conserved during evolution and show no similarity to other known proteins. We have shown that BRINP family proteins suppress cell cycle progression of various cell types including differentiating neural stem cells [4]. Hence we propose that BRINP family proteins are involved in the key events of neural development, such as cessation of cell proliferation and neuronal differentiation. BRINP family mRNA expression is also observed in neuronal cell layers and nuclei of the adult brain [4]. These finding suggests that BRINP family genes also play an important role in the adult brain presumably in neuronal cells. However, there is little information about the physiological roles of the BRINP family genes in adult neural tissue. In the present study, we investigated the regulation of BRINP family mRNA expression in response to glutamate-induced neural activity both in vivo and in vitro. 


\section{MATERIALS AND METHODS}

\subsection{Animal use and kainic acid administration.}

All experimental protocols on animals were reviewed and approved by the Animal Care and Use Committee of Hokkaido University. Adult C57BL/6 mice (female, 16-20 g; CLEA Japan, Inc.) were injected intraperitoneally with kainic acid (KA, 20mg/kg; Sigma). At 1 hr after the KA injection, the seizure activity of all injected mice ranged from mild to severe based on the scale of Morrison et al. [6].

\subsection{Preparation of $c R N A$ probes.}

The cRNA probe for each BRINP family gene was synthesized using DIG -RNA labeling mix according to the manufacture's instruction (Roche). Each probe was designed according to the following sequences: nucleotide residues 1678-2716 of BRINP1 cDNA (AB060589), 2589-3223 of BRINP2 cDNA (AB077853), and 439-1086 of BRINP3 cDNA (ABO77854), respectively. A sense cRNA probe transcribed from the each BRINP-cDNA was used as the negative control.

\subsection{In situ hybridization analysis.}

Animals were anesthetized with a pentobarbital sodium and exsanguinated by intracardiac perfusion with PBS, followed by fixation with perfusion of $4 \%$ paraformaldehyde. Each sample was cut into $12-\mu \mathrm{m}$-thick sections. Sections were processed for fixation, acetylation, prehybridization, and hybridization as described previously [7].

\subsection{Cell cultures.}

Primary cultures of mouse hippocampal neurons were prepared as described by Brewer 
et al. [8]. In brief, the hippocampi were dissected from 17-day embryos and incubated in $\operatorname{DMEM}$ (Sigma) containing $0.25 \%$ Trypsin (Gibco) for $15 \mathrm{~min}$ at $37^{\circ} \mathrm{C}$. Next the cells were dissociated by mechanical tritulation and after being washed with DMEM, they were suspended in Neurobasal medium (Gibco) supplemented with 2\% B27 supplement (Gibco), $500 \mu \mathrm{M}$ L-glutamine (Sigma), $25 \mu \mathrm{M}$ glutamic acid (Sigma), $100 \mu \mathrm{g} / \mathrm{ml}$ streptomycin, and 50 $\mathrm{U} / \mathrm{ml}$ penicillin. The cells were plated onto poly-L-lysine $(0.1 \mathrm{mg} / \mathrm{ml}$; Sigma $)$ coated $35 \mathrm{~mm}$ plastic dishes at 60,000 cells/dish. At 5 days in vitro (5 DIV), the cultures were stimulated with various compounds at the concentration indicated in the figures. A dissociated culture of astrocytes was also prepared from 17-day embryos and maintained in DMEM containing $10 \%$ fetal bovine serum.

\subsection{RT-PCR analysis}

Total RNA was extracted from the hippocampal tissue and cultured cells with Trizol reagent (Invitrogen). Total RNA $(0.5 \mu \mathrm{g})$ was subjected to cDNA synthesis using

ImProm-II ${ }^{\mathrm{TM}}$ reverse transcriptase (Promega) and random primer (Promega). A quantitative analysis of the mRNA levels was performed on Opticon Real-Time PCR (MJ Research) using sequence-specific primer pairs: BRINP 1: 5'-ACCGGCAAGGATTTACAACC-3' and 5'-CTTTGAAACTCCGGCATGA-3'; BRINP2: 5'-TGGGAGTCTCCTCGCAGTC-3' and 5'-TTCTCCCAGGCGGTTAGTGT-3'; BRINP3: 5'-CATCAGCCTGCCGAGACA-3' and 5'-GAGTGGGTTTCCTCGGAGAA-3'; BDNF: 5'- CCATAAGGACGCGGACTTGT-3' and 5'- GCGCCGAACCCTCATAGACAT-3'. PCR was carried out on duplicate cDNA samples using SYBR Green Master Mix (Finnzymes) according to the protocol of the manufacturer. GAPDH was used as the control. 


\subsection{Immunocytochemistry.}

Cultured cells were fixed with 4\% paraformaldehyde in PBS for 20 min at room temperature. After permeabilization and blocking, samples were incubated with PBS containing $1 \%(\mathrm{w} / \mathrm{v}) \mathrm{BSA}$ and the following primary antibodies for $1 \mathrm{hr}$ at room temperature: anti-glial fibrillary acidic protein (GFAP) (Dako) and anti-microtubule associated protein 2 (MAP2) (Up-state). After washing, samples were incubated with Alexa488-conjugated goat anti-rabbit IgG (Molecular Probes) and cy3-conjugated goat anti-mouse IgG (Jackson) for 30 min at room temperature.

\subsection{Statistical analysis.}

Quantitative data are presented as mean $\pm \operatorname{SEM}(\mathrm{n} \geq 3)$. Statistical analysis was performed according to Fisher's protected least-significant difference (Fisher's PLSD). 


\section{RESULTS}

\subsection{Regulation of BRINP family mRNA in adult mouse brain}

To better evaluate the possible physiological roles of BRINP family genes in the adult brain, we analyzed the regulation of BRINP family gene expression in response to the activation of glutamate receptors. In situ hybridization experiments showed that cells expressing BRINP1, 2, and 3-mRNA were broadly observed in neuronal cell layers and nuclei in various regions of the vehicle-injected mouse brain (Fig. 1A, B, C, E). At $6 \mathrm{hr}$ after the KA injection, of the three BRINP genes, BRINP1-mRNA was specifically up-regulated in the hippocampus, especially in the dentate gyrus (Fig. 1G). This increase of BRINP1-mRNA in the dentate gyrus was observed at $3 \mathrm{hr}$ after the injection, peaking at $6 \mathrm{hr}$ and its expression level returned to the basal level at $12 \mathrm{hr}$ (Fig. 1F-I). In contrast, there was no significant change in BRINP2- and BRINP3-mRNA levels in whole mice brain regions including the hippocampus after the KA injection (data not shown).

Quantitative RT-PCR experiments using total RNA samples prepared from the dissected hippocampus showed that the BRINP1-mRNA level in the KA-treated hippocampus was three times that of the vehicle-treated mice at $6 \mathrm{hr}$ after the injection (Fig. 1K), consistent with the results of the in situ hybridization experiment. On the other hand, BRINP2- and BRINP3-mRNA levels were slightly down-regulated at $6 \mathrm{hr}$ after the KA injection. The time course of the KA-induction of BRINP1-mRNA in mice brain was similar to that of the KA-induction of BDNF-mRNA (Fig. 1L) as reported by Zafra et al. previously [9].

\subsection{Regulation of BRINP family mRNA in cultured hippocampal neurons}

To further investigate regulation of the BRINP family genes by activation of glutamate receptors, we used the primary culture of embryonic mice hippocampal neurons. The 
hippocampal cells were subjected to KA administration at 5 DIV when neuronal cells had established a fine network of neurites (Fig.2E). As shown in Figure 2A, quantitative RT-PCR experiments indicated that the BRINP1-mRNA levels in primary cultured hippocampal neurons were up-regulated at $6 \mathrm{hr}$ after KA administration in a dose-dependent manner. The maximal increase of BRINP1-mRNA was obtained with $50 \mu \mathrm{M} \mathrm{KA}$, and a further increase in the KA concentration led to a gradual decrease of the expression level. On the other hand, BRINP2- and BRINP3-mRNAs were not up-regulated significantly by any dose of KA. Then we investigated the time-course of the changes in the BRINP family mRNA levels after administration of $50 \mu \mathrm{M}$ KA (Fig.2C). The up-regulation of BRINP1-mRNA by KA was observed from $3 \mathrm{hr}$ of administration. The level of BRINP1-mRNA at $6 \mathrm{hr}$ after KA administration was three times that of the control culture, and the elevated BRINP1-mRNA levels were maintained until $12 \mathrm{hr}$ after administration, but its expression level returned to the basal level by $18 \mathrm{hr}$. The high expression levels of BRINP1-mRNA sustained for a longer period after KA administration suggest that the desensitizing mechanisms of either the relevant glutamate receptors or the intracellular signaling machinery is still immature or dysfunctional at 5 DIV compared to the adult hippocampal neurons in vivo. The expression levels of the other two BRINP-mRNAs were not up-regulated significantly by KA over $12 \mathrm{hrs,} \mathrm{although} \mathrm{a} \mathrm{slight} \mathrm{down-regulation} \mathrm{of}$ BRINP2-mRNA levels was observed (Fig. 2C). Induction of BDNF-mRNA by KA in the primary hippocampal culture was similar to that of BRINP1-mRNA with regard to the timeand dose-dependence of the KA treatment (Fig. 2B, D) [9].

We then examined the cellular components of the primary hippocampal culture. As shown in figure $2 \mathrm{E}$, our primary hippocampal culture contained $\geq 90 \%$ neurons, although small numbers of GFAP-positive astrocytes $(<10 \%)$ were also observed. To investigate the 
possible expression of the BRINP family gene in astrocytes, we prepared an astrocyte-rich $(\geq 99 \%)$ culture from the embryonic mouse cerebral cortex (Fig. 2F). As shown in Figure 2G, the basal level of BRINP1-mRNA in the astrocyte-rich culture was much lower than that in the neuron-rich culture. Furthermore, no up-regulation of BRINP1-mRNA by KA treatment was observed in the cultured astrocytes. Therefore, the up-regulation of the BRINP1-mRNA levels is attributed to the response of the cultured hippocampal neurons.

To investigate the cellular signaling mechanisms leading to the induction of BRINP1-mRNA, we then treated the cultured hippocampal neurons with various glutamate receptor agonists and antagonists. As shown in Figure 3A, induction of BRINP1-mRNA by KA was antagonized by CNQX, a non- N-methyl-D-aspartic acid (NMDA) receptor-specific antagonist. Interestingly, NMDA also up-regulated BRINP1-mRNA to an extent similar to that of KA, and the NMDA evoked up-regulation was antagonized by MK-801, a NMDA receptor-specific antagonist. There was no significant change in BRINP1-mRNA levels in the presence of CNQX or MK-801 alone. These results clearly indicate that the activity-dependent up-regulation of BRINP1-mRNA occurs not only through activation of the KA receptors but also through activation of the NMDA receptors. Since both the KA and NMDA receptors are members of ionotropic glutamate receptors that cause a net influx of $\mathrm{Ca}^{2+}$ which is known to be a key regulator of the activity-dependent induction of neuronal genes such as BDNF, it is speculated that the influx of $\mathrm{Ca}^{2+}$ also serves as a major intracellular signal for the induction of BRINP1 $[3 ; 10]$. So, we examined the effects of high concentrations of $\mathrm{KCl}$, which causes membrane depolarization and the influx of $\mathrm{Ca}^{2+}$, on the levels of BRINP1-mRNA. At $6 \mathrm{hr}$ after addition of $\mathrm{KCl}$ to the culture medium, the BRINP1-mRNA level increased to four times that of the control culture and this increase was inhibited by nifedipine, a blocker for the L-type voltage sensitive calcium channel, although a 
fraction of the KCL induced BRINP1-mRNA level still remained (Fig. 3B). These results indicate that membrane depolarization can induce BRINP1-mRNA mainly through the influx of $\mathrm{Ca}^{2+}$.

\subsection{The regulation of BRINP1-mRNA by members of neurotrophin and TGF $\beta$ family.}

The above results indicate that the activity-dependent inductions of BRINP1-mRNA and BDNF-mRNA have common features such as activation by agonists of ionotropic glutamate receptors and the role of intracellular $\mathrm{Ca}^{2+}[9 ; 11 ; 12]$. In addition, BRINP gene expression is regulated by extrinsic factors such as members of the neurotrophin and TGF $\beta$ family in the developmental stage [4]. We then examined the effects of those factors on the levels of BRINP1-mRNA in the cultured hippocampal neurons. Although BDNF-, NGF-, and activin A-mRNA are known to be induced in the hippocampus in an activity-dependent manner, none of these factors up-regulated the BRINP1-mRNA level at $6 \mathrm{hr}$ after administration (Fig. 4)

[12; 13]. In contrast, NT-3 slightly induced BRINP1-mRNA in cultured hippocampal neurons. In this context, it is interesting to note that NT-3-mRNA has been reported to be down-regulated by various neural activities, including administration of glutamate in vivo [12]. Therefore, the activity-dependent induction of BRINP1-mRNA may be independent from the action of these factors, although the basal level of BRINP1-mRNA may well be regulated by them. We also examined the effects of BMP2 which possesses the ability to induce BRINP1-mRNA in developing sympathetic neurons [4]. However, BMP2 had no effect on BRINP1-mRNA levels in the cultured hippocampal neurons. 


\section{DISCUSSION}

Administration of glutamate receptor agonists is a commonly used method to investigate activity-dependent events in the CNS, such as neural apoptosis, synaptic plasticity, and neurogenesis in the hippocampus [14-16]. For example, administration of KA induces neuronal apoptosis in pyramidal neurons in the CA1-3 region [14]. KA administration is also known to cause mossy fiber sprouting and up-regulation of KA receptor density that consequently leads to the modification of glutaminergic synaptic transmission in the hippocampus [16]. In addition, Dong et al. reported that KA administration resulted in the promotion of hippocampal neurogenesis to replace degenerating neurons caused by the excitotoxicity-induced apoptosis [15]. In the present study, we have demonstrated the specific induction of BRINP1-mRNA in the granular cell layer of the dentate gyrus by the administration of KA. The activity-dependent induction of BRINP1-mRNA suggests several possibilities for the physiological functions of the BRINP1 gene product in adult neural tissue.

First, the activity-dependent induction of BRINP1 gene may play a neuroprotective role.

So far, a number of studies have shown that hyper activation of neurons in pathological conditions such as neural ischemia and trauma leads to apoptosis in various brain regions, especially in the hippocampus [17]. Copani et al. demonstrated that neuronal apoptosis induced by hyper activation was related to an inappropriate re-entry of neurons into the cell cycle $[18 ; 19]$. Under the normal state of the adult brain, terminally-differentiated neurons are thought to be arrested in the quiescent phase (Go) of the cell cycle. Hyper activation of these neuronal cells can, however, induce expression of cell cycle signaling molecules such as cyclin D1, which is known to play a key role in the G1/S transition of cell cycle progression. The aberrant re-entry of the neurons into the cell cycle could easily disrupt the cell conformity and lead to cell death. Park et al. reported that the induction of cyclin-dependent kinase 
inhibitors (CDKIs) prevents the re-entry of neurons into the cell cycle and the resulting neuronal cell death evoked by neurotrophic factor withdrawal [20]. However, the ectopic expression of any single known cell cycle regulator is not sufficient to prevent neuronal cell death in general [18]. Given the ability of BRINPs to arrest cell cycle progression at G1/S transition, the up-regulated BRINP1 may well serve as a neuroprotective factor through suppression of cell cycle progression in cooperation with other cell cycle regulators such as CDKIs. The preferential induction of BRINP1-mRNA in the dentate gyrus, a region that is relatively resistant to excito-toxicity, also implies a neuroprotective role of BRINP1 against the activity-driven cell cycle re-entry of neuronal cells.

Second, the activity-dependent induction of the BRINP1 gene can be associated with synaptic plasticity. The expression level of BRINP1-mRNA in the brain dramatically increases from E16 and reaches a maximal level between postnatal days 6 and 9 [4]. The period of BRINP1-mRNA high expression levels coincides with the period when immature neurons actively extend dendrites and spines and exert giant depolarizing potentials (GDP) to achieve synaptic connections and functional maturation [21]. During the postnatal period, the BRINP1-mRNA level gradually decreases toward adulthood. In adulthood, however, the BRINP1 gene can be re-induced by neural activity in a similar manner to the BDNF gene which is known to play a fundamental role in synaptic plasticity [1;22]. These observations suggest that the BRINP1 gene product also plays a role in synaptic development and plasticity during the developmental stage and in adulthood.

Finally, the activity-dependent induction of the BRINP1 gene can be associated with neurogenesis in adult neural tissue. Several regions of the adult mammalian CNS, including the dentate gyrus of the hippocampus, retain the capacity for neurogenesis which would contribute to the plasticity of the neural circuitry system such as learning and memory 
formation [23]. It has been shown that KA administration increases the rate of neurogenesis within the dentate gyrus [15]. It is hence plausible that BRINP 1 induced by augmented neural activity in the adult brain plays a role in the process of activity-induced neurogenesis in the dentate gyrus in a similar manner to that during the developmental stage i.e. suppression of cell cycle progression in newly created neuronal cells. It is speculated that adult neurogenesis plays both a pathological role such as replacement and compensation of degenerating neurons and a physiological role such as learning and memory formation [23; 24]. Hence, a possible association of BRINP1 expression with adult neurogenesis should be considered with regard to both situations.

In summary, our results demonstrate for the first time that expression of BRINP1-mRNA is specifically regulated by neural activity in hippocampal neurons. It is highly likely that the activity-dependent induction of BRINP1-mRNA has important physiological roles, such as neuroprotection, neural regeneration, and synaptic plasticity in the adult brain. Although, in the present study, the mode of BRINP gene expressions was analyzed at an mRNA level, it is necessary to clarify the protein dynamics such as translation, post-translational modification and interaction with other proteins to fully assign their physiological roles in the CNS. It will also be beneficial to examine the loss of BRINP gene functions by application of gene knockout and knockdown technology, which is currently underway.

\section{Acknowledgements}

The authors are grateful to Ms. Sharon Hanley (Asahikawa Medical College) for correcting their use of language. 


\section{Reference List}

[1] A.F.Schinder, M.Poo, The neurotrophin hypothesis for synaptic plasticity Trends Neurosci. 23, (2000) 639-645.

[2] J.G.Hunsberger, A.H.Bennett, E.Selvanayagam, R.S.Duman, S.S.Newton, Gene profiling the response to kainic acid induced seizures Brain Res.Mol.Brain Res. 141, (2005) 95-112.

[3] A.E.West, W.G.Chen, M.B.Dalva, R.E.Dolmetsch, J.M.Kornhauser, A.J.Shaywitz, M.A.Takasu, X.Tao, M.E.Greenberg, Calcium regulation of neuronal gene expression Proc.Natl.Acad.Sci.U.S.A 98, (2001) 11024-11031.

[4] H.Kawano, T.Nakatani, T.Mori, S.Ueno, M.Fukaya, A.Abe, M.Kobayashi, F.Toda, M.Watanabe, I.Matsuoka, Identification and characterization of novel developmentally regulated neural-specific proteins, BRINP family Brain Res.Mol.Brain Res. 125, (2004) $60-75$.

[5] N.Toshiyuki, M.Ichiro, Molecular mechanisms regulating cell type specific expression of BMP/RA Inducible Neural-specific Protein-1 that suppresses cell cycle progression: roles of NRSF/REST and DNA methylation Brain Res.Mol.Brain Res. 125, (2004) 47-59.

[6] R.S.Morrison, H.J.Wenzel, Y.Kinoshita, C.A.Robbins, L.A.Donehower, P.A.Schwartzkroin, Loss of the $\mathrm{p} 53$ tumor suppressor gene protects neurons from kainate-induced cell death J.Neurosci. 16, (1996) 1337-1345.

[7] B.M.Schmitt, U.V.Berger, R.M.Douglas, M.O.Bevensee, M.A.Hediger, G.G.Haddad, W.F.Boron, $\mathrm{Na} / \mathrm{HCO} 3$ cotransporters in rat brain: expression in glia, neurons, and choroid plexus J.Neurosci. 20, (2000) 6839-6848.

[8] G.J.Brewer, J.R.Torricelli, E.K.Evege, P.J.Price, Optimized survival of hippocampal 
neurons in B27-supplemented Neurobasal, a new serum-free medium combination J.Neurosci.Res. 35, (1993) 567-576.

[9] F.Zafra, B.Hengerer, J.Leibrock, H.Thoenen, D.Lindholm, Activity dependent regulation of BDNF and NGF mRNAs in the rat hippocampus is mediated by non-NMDA glutamate receptors EMBO J. 9, (1990) 3545-3550.

[10] P.B.Shieh, A.Ghosh, Molecular mechanisms underlying activity-dependent regulation of BDNF expression J.Neurobiol. 41, (1999) 127-134.

[11] O.Lindvall, P.Ernfors, J.Bengzon, Z.Kokaia, M.L.Smith, B.K.Siesjo, H.Persson, Differential regulation of mRNAs for nerve growth factor, brain-derived neurotrophic factor, and neurotrophin 3 in the adult rat brain following cerebral ischemia and hypoglycemic coma Proc.Natl.Acad.Sci.U.S.A 89, (1992) 648-652.

[12] J.M.Canals, S.Marco, N.Checa, A.Michels, E.Perez-Navarro, E.Arenas, J.Alberch, Differential regulation of the expression of nerve growth factor, brain-derived neurotrophic factor, and neurotrophin-3 after excitotoxicity in a rat model of Huntington's disease Neurobiol.Dis. 5, (1998) 357-364.

[13] Y.P.Tretter, M.Hertel, B.Munz, B.G.ten, S.Werner, C.Alzheimer, Induction of activin A is essential for the neuroprotective action of basic fibroblast growth factor in vivo Nat.Med. 6, (2000) 812-815.

[14] P.Giusti, M.Lipartiti, D.Franceschini, N.Schiavo, M.Floreani, H.Manev, Neuroprotection by melatonin from kainate-induced excitotoxicity in rats FASEB J. 10, (1996) 891-896.

[15] H.Dong, C.A.Csernansky, B.Goico, J.G.Csernansky, Hippocampal neurogenesis follows kainic acid-induced apoptosis in neonatal rats J.Neurosci. 23, (2003) 1742-1749.

[16] Y.Ben-Ari, R.Cossart, Kainate, a double agent that generates seizures: two decades of 
progress Trends Neurosci. 23, (2000) 580-587.

[17] K.Herrup, R.Neve, S.L.Ackerman, A.Copani, Divide and die: cell cycle events as triggers of nerve cell death J.Neurosci. 24, (2004) 9232-9239.

[18] A.Copani, D.Uberti, M.A.Sortino, V.Bruno, F.Nicoletti, M.Memo, Activation of cell-cycle-associated proteins in neuronal death: a mandatory or dispensable path? Trends Neurosci. 24, (2001) 25-31.

[19] D.X.Liu, L.A.Greene, Neuronal apoptosis at the G1/S cell cycle checkpoint Cell Tissue Res. 305, (2001) 217-228.

[20] D.S.Park, B.Levine, G.Ferrari, L.A.Greene, Cyclin dependent kinase inhibitors and dominant negative cyclin dependent kinase 4 and 6 promote survival of NGF-deprived sympathetic neurons J.Neurosci. 17, (1997) 8975-8983.

[21] Y.Ben-Ari, Developing networks play a similar melody Trends Neurosci. 24, (2001) $353-360$.

[22] V.R.Rao, S.A.Pintchovski, J.Chin, C.L.Peebles, S.Mitra, S.Finkbeiner, AMPA receptors regulate transcription of the plasticity-related immediate-early gene Arc Nat.Neurosci. 9, (2006) 887-895.

[23] P.M.Lledo, M.Alonso, M.S.Grubb, Adult neurogenesis and functional plasticity in neuronal circuits Nat.Rev.Neurosci. 7, (2006) 179-193.

[24] J.Liu, K.Solway, R.O.Messing, F.R.Sharp, Increased neurogenesis in the dentate gyrus after transient global ischemia in gerbils J.Neurosci. 18, (1998) 7768-7778. 


\section{Legends to figures}

Fig. 1. A-J. In situ hybridization of BRINP family-mRNA in the brain of vehicle or kainic acid treated mice. A-C. Cells expressing BRINP1 (BR1), BRINP2 (BR2), and BRINP3 (BR3)-mRNA are broadly observed in neuronal cell layers and nuclei in various region of vehicle treated mouse brain (Cont.). E-I. At $6 \mathrm{hr}$ after KA injection, BRINP1-mRNA was specifically up-regulated in the hippocampus, especially in the dentate gyrus. The increase of BRINP1-mRNA in the dentate gyrus was observed from $3 \mathrm{hr}(\mathrm{F})$ after injection, peaking at $6 \mathrm{hr}(\mathrm{G}) . \quad$ BRINP1-mRNA expression returned to basal level at $12 \mathrm{hr}(\mathrm{H}) . \quad$ D and J.

Negative control with a sense probe (BRINP1). Scale bar: $1 \mathrm{~mm}(\mathrm{D}), 500 \mu \mathrm{m}(\mathrm{J}) . \quad \mathrm{K}$ and L. Quantitative RT-PCR analysis of BRINP- and BDNF-mRNA in hippocampal tissue of the KA or vehicle treated mice. K. BRINP family mRNA (BRINP1: ${ }^{*} \mathrm{P}<0.05$, vs. control and KA3hr, KA12hr, KA24 hr; BRINP3: ${ }^{~} \mathrm{P}<0.05$, vs. control, KA3hr, KA24 hr). $\quad$ L. BDNF-mRNA $(* \mathrm{P}<0.05$, vs. control, KA12hr, KA24 hr).

Fig. 2. A-D. Quantitative RT-PCR analysis of BRINP- and BDNF-mRNA in cultured hippocampal neurons. A and B. Dose-dependent increase of BRINP- and BDNF-mRNA at 6 hr of the KA-treatment. A. BRINP family mRNA (BRINP1: ${ }^{*} \mathrm{P}<0.05$, vs. control, BRINP2: \#, $\mathrm{P}<0.05$, vs. control). B. BDNF-mRNA ( ${ }^{*} \mathrm{P}<0.05$, vs. control). $\quad$ C and D. Time course of the increase of BRINP- and BDNF-mRNA after administration of $50 \mu \mathrm{M} \mathrm{KA} . \quad \mathrm{C}$. BRINP family mRNA (BRINP1: ${ }^{*} \mathrm{P}<0.05$, vs. control, BRINP2: \#P<0.05, vs. control). $\quad \mathrm{D}$. BDNF-mRNA $(* \mathrm{P}<0.05$, vs. control). E-G. Comparison between neuronal and glial cultures. E. The primary hippocampal neuronal culture contained $\geq 90 \%$ MAP2-positive neurons (red) and $\leq 10 \%$ GFAP-positive astrocytes (green) at 5 DIV. F. The glial culture contained $\geq 99 \%$ GFAP-positive astrocytes (green). G. Quantitative RT-PCR analysis indicated that the basal 
level of the glial culture was much lower than that in the neuronal culture and there was no up-regulation of BRINP 1-mRNA by the KA treatment $(50 \mu \mathrm{M})$ in the glial culture. Scale bar equals $50 \mu \mathrm{m}$ both in (E) and (F).

Fig. 3. A. Effects of various agonists and antagonists of glutamate receptors on BRINP1-mRNA levels. The cultured hippocampal neurons are incubated with CNQX (10 $\mu \mathrm{M})$ or MK-801 $(10 \mu \mathrm{M})$ for 15 minutes prior to the $\mathrm{KA}(50 \mu \mathrm{M})$ or NMDA $(50 \mu \mathrm{M})$ treatment for 6 hr. $\quad\left({ }^{*} \mathrm{P}<0.05\right.$, vs. KA with $\mathrm{CNQX} . \quad \# \mathrm{P}<0.05$, vs. NMDA with MK-801). B. Effects of depolarization and influx of $\mathrm{Ca}^{2+}$ on BRINP1-mRNA levels. The cultured hippocampal neurons are incubated with $10 \mathrm{mM} \mathrm{KCl}$ for $6 \mathrm{hr}$ with or without $10 \mu \mathrm{M}$ nifedipine $\left({ }^{*} \mathrm{P}<0.05\right.$, vs. a group without $\mathrm{KCl}$ treatment and a group with both $\mathrm{KCl}$ and nifedipine treatment. $\quad \# \mathrm{P}<0.05$, vs. a group without treatment and a group with nifedipine alone).

Fig. 4. Effects of various members of the neurotrophin and TGF- $\beta$ family on BRINP1-mRNA levels. The cultured hippocampal neurons are incubated for $6 \mathrm{hr}$ in the presence of KA $(50 \mu \mathrm{M})$, BDNF (50 ng/ml), NGF (50 ng/ml), NT-3 (50 ng/ml), activin A (10 $\mathrm{ng} / \mathrm{ml})$, and BMP-2 (10 ng/ml) $(* \mathrm{P}<0.05$, vs. control). 
Fig. 1. Motomiya et al.
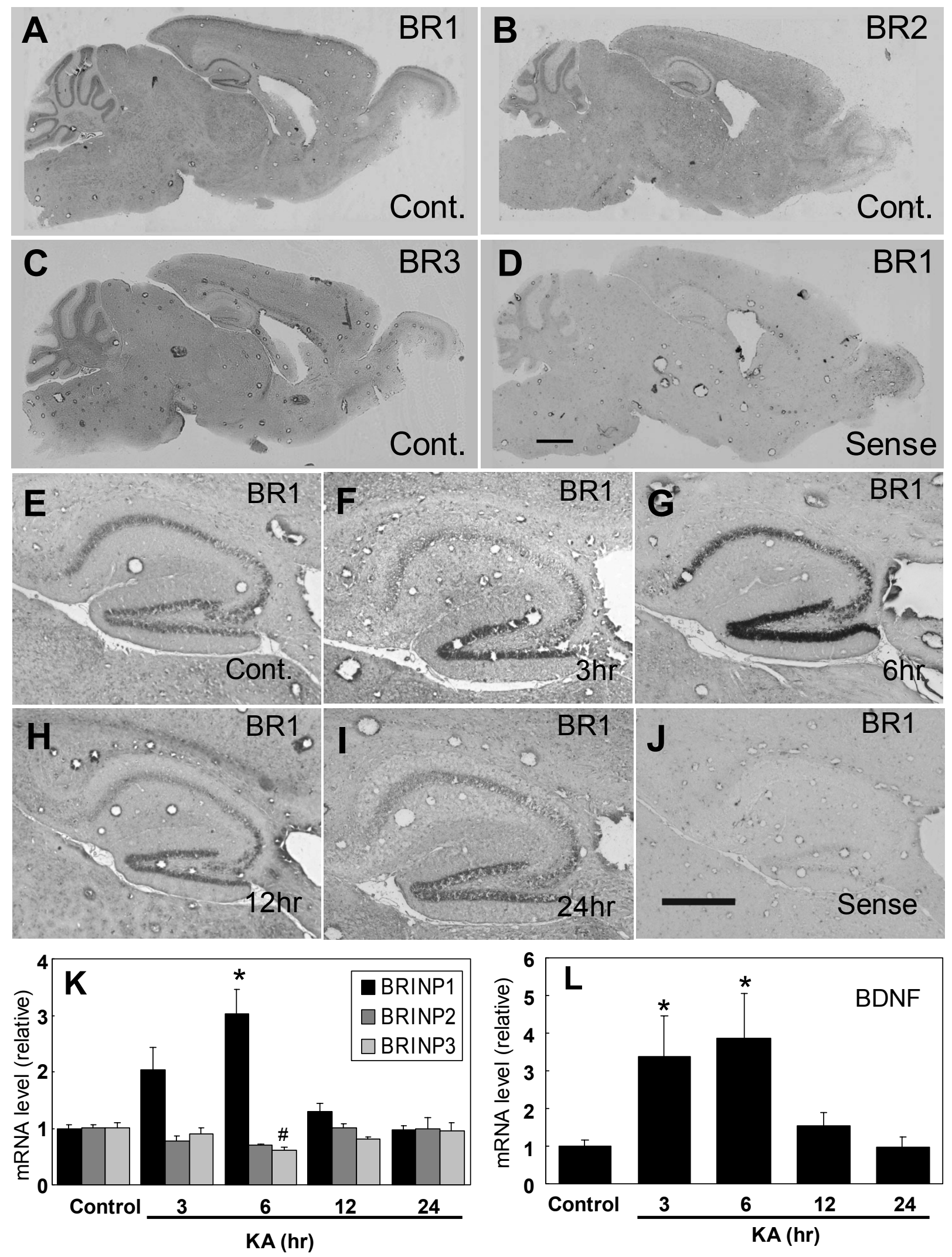
Fig. 2. Motomiya et al.
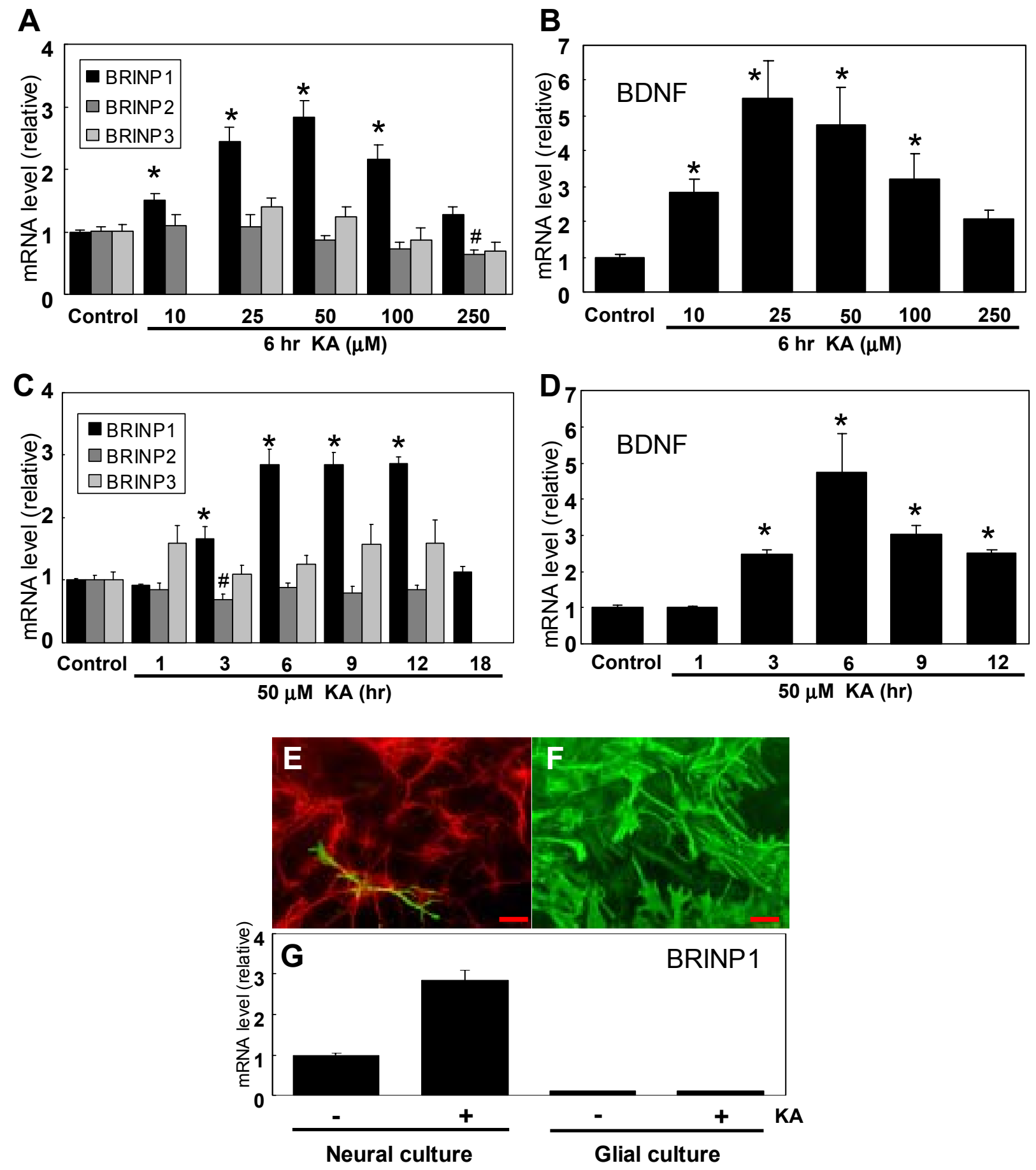
Fig. 3. Motomiya et al.

A

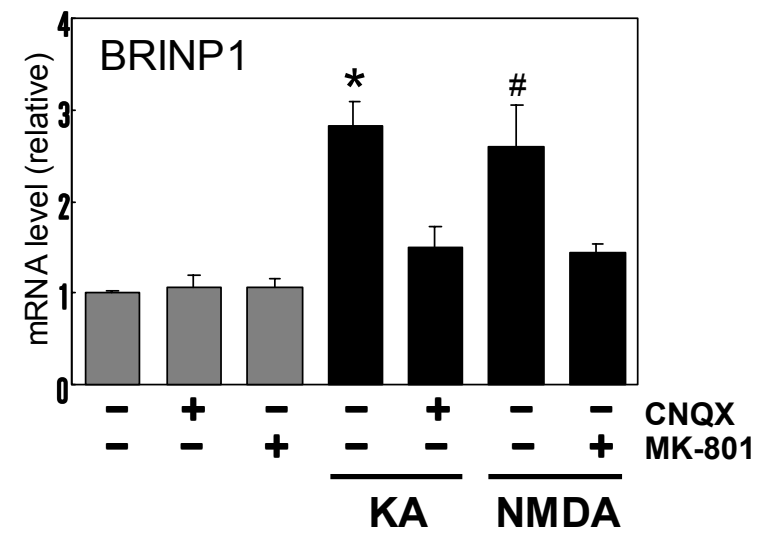

B

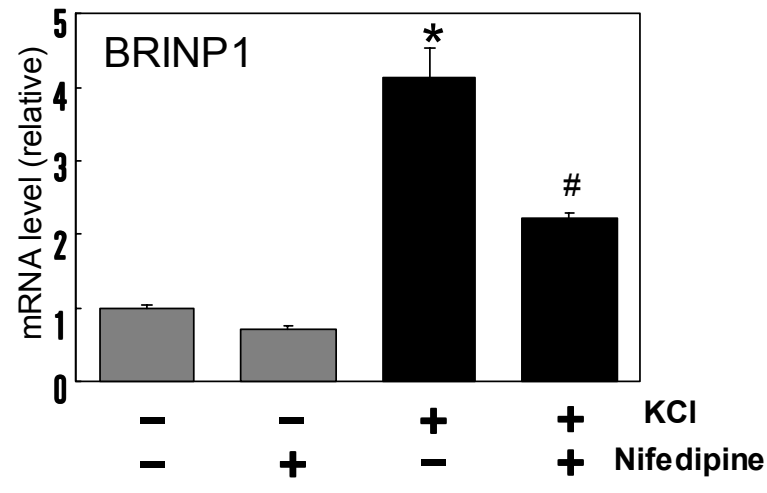


